Agronomía Costarricense 37(1): 39-50. ISSN:0377-9424 / 2013

www.mag.go.cr/rev_agr/index.html www.cia.ucr.ac.cr

\title{
IDENTIFICACIÓN DEL AGENTE CAUSAL DE LA ANTRACNOSIS DE Sansevieria spp. EN COSTA RICA
}

\author{
Gerardo Pérez-León ${ }^{*}$ Lourdes Chavarría-Pérez ${ }^{* *}, J_{u l i o}$ Araya-Quesada ${ }^{* *}$, Luis Gómez-Alpízar ${ }^{1 * *}$ \\ Palabras clave: Colletotrichum sansevieriae, enfermedad, ITS, ornamental. \\ Keywords: Colletotrichum sansevieriae, disease, ITS, ornamental. \\ Recibido: 13/09/13 \\ Aceptado: 12/02/13
}

\section{RESUMEN}

Sansevieria spp. (Agavaceae) es una ornamental de follaje originaria de África y Asia. $S$. trifasciata (St) es la especie con mayor número de cultivares en el mercado de exportación de Costa Rica a Estados Unidos y Holanda. Muestras foliares de S. trifasciata var. "Hahnii" con lesiones circulares y acuosas (algunas alargadas y secas), fueron analizadas. El patógeno recuperado fue identificado como Colletotrichum sansevieriae Nakamura $(C s \mathrm{~N})$ mediante pruebas de patogenicidad, morfología y técnicas moleculares. Los aislamientos mono-hifales presentaron coloración crema, crecimiento postrado y escasa producción de conidios. La patogenicidad de $C s \mathrm{~N}$ se evaluó en 7 variedades de St; Sansevieria sp., var., jiboia; $S$. cylindrica y las ornamentales Codiaeum variegatum, Cordelyne terminalis y Dracaena deremensis, mediante 2 sistemas de inoculación: plantas en maceta (invernadero) y hojas separadas (laboratorio); con ambos se reprodujeron los síntomas de la enfermedad. Cinco de las variedades de S. trifasciata desarrollaron síntomas, "Hahnii" la más susceptible. Ninguna de las otras ornamentales presentó síntomas. $C s \mathrm{~N}$ fue re-aislado de hojas inoculadas (postulados de Koch). La amplificación mediante PCR de la región ITS con los iniciadores ITS5 e ITS4 produjo un fragmento de aproximadamente $600 \mathrm{pb}$, cuya secuencia de nucleótidos fue idéntica para los aislamientos mono-hifales. En el Banco

1/ Autor para correspondencia. Correo electrónico: luis.gomezalpizar@ucr.ac.cr

Centro de Investigaciones Agronómicas, Universidad de Costa Rica. San José, Costa Rica.

\begin{abstract}
Identification of the agent causing anthracnose on Sansevieria spp., in Costa Rica. Sansevieria spp. (Agavaceae), native to Africa and Asia, is a foliage ornamental known as "mother-in-law's tongue" or sansevieria. $S$. trifasciata $(S t)$ is the species with the highest number of cultivars on the Costa Rican export market. (to the United States and the Netherlands). Leaf samples of $S$. trifasciata var. "Hahnii" with circular and aqueous lesions, (some dried and elongated) were analyzed. From infected tissue five mono-hyphal isolates were obtained. The pathogen was identified as Colletotrichum sansevieriae Nakamura $(C s \mathrm{~N})$ on the basis of pathogenicity tests, morphology and molecular techniques. Colonies were cream-colored, flat and produced few conidia. The pathogenicity of the isolates was assessed on 7 varieties of $S t$; Sansevieria sp., var. Jiboia; S. cylindrica and the ornamentals Codiaeum variegatum, Cordelyne terminalis and Dracaena deremensis through greenhouse (pot) and laboratory (separate leaves) inoculations. In both conditions disease symptoms were reproduced. Five of the $S$. trifasciata varieties evaluated developed symptoms, var. "Hahnii" the most susceptible. The same pathogen was re-isolated from inoculated leaves (Koch's postulates). PCR amplification of the ITS region with starters ITS5 and ITS4 yielded a single fragment of approximately 600 base
\end{abstract}

** Florica Farms S.A., Palmares, Costa Rica. 
de Genes, la secuencia alineó con accesiones de $C s \mathrm{~N}$ de Australia y USA, con un índice de similaridad del 99 al 100\%. El análisis filogenético, con base en la región ITS2, agrupó (99\% valor de bootstrap) los aislamientos costarricenses con el aislamiento tipo $C s \mathrm{~N}$ de Japón y los de Australia y USA. Hasta donde se conoce, éste es el primer informe de la antracnosis de Sansevieria en C. R.

\section{INTRODUCCIÓN}

El subsector agrícola ornamental costarricense, que incluye plantas, flores y follajes, ha logrado un marcado desarrollo en las últimas décadas como productos de exportación no tradicional. En el período 2006-2010, la participación relativa promedio en las exportaciones del país fue de un $2,0 \%$, con un valor promedio de 181,9 millones de dólares americanos (PROCOMER 2010, Mora 2008). Dentro de este componente, las plantas ornamentales, particularmente las comercializadas por el atractivo de su follaje (plantas u ornamentales de follaje), constituyen el $40 \%$ de las exportaciones. Los Estados Unidos de América (USA) y Holanda son los principales destinos de exportación de la producción costarricense de este tipo de plantas (PROCOMER 2010, Mora 2008).

Sansevieria spp., (Agavaceae) es un género de plantas herbáceas, perennes, xerofíticas, rizomatosas o estoloníferas, acaules o con un tallo muy corto, apreciadas como ornamentales de follaje debido a la variegación, moteado y amplia variación en la forma de sus hojas, aplanadas, semi-cilíndricas, cilíndricas, comprimidas lateralmente, de lineares a lanceoladas u ovadas; erectas, rígidas o flexibles (Takawira y Nordal 2001, Khalumba et ál. 2005, Sánchez 2006). En adición, son plantas de interior resistentes, de fácil mantenimiento. Son populares como plantas de interior para jardinera o maceta. Las hojas erectas, puntiagudas y moteadas son también pairs. Sequences of the ITS regions of isolates were identical. Sequences exhibited 99-100\% nucleotide identity to isolates of $C s \mathrm{~N}$ collected from diseased sansevieria in Australia and USA. Phylogenetic analysis, based on ITS2 region, indicates that the Costa Rican isolates clustered ( $99 \%$ bootstrap support) with the type species $C s \mathrm{~N}$ from Japan and Australia and USA isolates. To our knowledge, this is the first report of $C s \mathrm{~N}$ causing anthracnose of Sansevieria in C.R.

utilizadas en arreglos florales (Takawira y Nordal 2001, Khalumba et ál. 2005, Sánchez 2006).

Se conocen comúnmente como Sansevieria, Rabo de tigre, Lengua de suegra, Lengua de vaca, Lengua del diablo, Espada de San Jorge, Planta serpiente, "Zebra Lily" y Planta de la suerte, entre otros. El género comprende entre 50 a 75 especies nativas del sur y este de África, Madagascar, Arabia, India y este de Asia (Takawira y Nordal 2001, Khalumba et ál. 2005, Sánchez 2006).

Sansevieria trifasciata es la especie más utilizada como ornamental y con mayor número de cultivares en el mercado. Las variedades más importantes son Laurentii, Black Coral y las Superbas. En Costa Rica, este tipo de follajes se producen para ser exportadas como plantas sin raíz. Las áreas de siembra se ubican mayoritariamente en la zona Huetar Norte, en los cantones de Sarapiquí, San Carlos, Río Cuarto de Grecia y Guatuso. Los distritos de la Tigra de San Carlos y Horquetas de Sarapiquí representan las áreas más importantes. Se cultivan 7 tipos de lengua de suegra, en orden de importancia Laurentii con un $41 \%$, Superba con un $31 \%$ y Black Coral con un $13 \%$ del área cultivada total de 22 hectáreas (MAG 2007, Mora 2008).

Nakamura et ál. 2006 describieron, por primera vez, la enfermedad foliar antracnosis de Sansevieria, causada por una nueva especie del género Colletotrichum, $C$. sansevieriae nov. La sintomatología descrita incluía lesiones iniciales redondas y acuosas, que luego se fusionan para dar lugar a daños mayores que provocan la 
"quema" de las hojas. Las lesiones se observan en todas las partes del follaje, tanto en hojas jóvenes como en maduras, cuando la infección está avanzada se observan chancros negros típicos de la antracnosis. Observaciones al microscopio permiten ver abundantes conidios del patógeno. Las unidades afectadas pierden su valor comercial. Pruebas de patogenicidad, en 20 plantas (ornamentales y vegetales) pertenecientes a 11 familias, mostraron que el hongo solo infectó las variedades de $S$. trifasciata, "Laurentii", "Hahnii" y "Golden Hahnii" y Sansevieria stuckyi. Luego del primer informe, en el 2008 se detectó el patógeno en Australia (Aldaoud et ál. 2011), en el 2010 en los Estados Unidos (Palmateer et ál. 2012).

El objetivo del presente trabajo fue aislar e identificar el patógeno asociado a los síntomas foliares. También se realizaron pruebas de patogenicidad en 7 variedades de $S$. trifasciata, así como en Sansevieria sp., var. Jiboia, S. cylindrica y en las ornamentales Codiaeum variegatum (Croton) Cordelyne terminalis (Cordelyne) y Dracaena deremensis (Janet Craig).

\section{MATERIALES Y MÉTODOS}

\section{Muestras}

A inicios del 2011 se recibieron en el Laboratorio de Biotecnología de Plantas del Centro de Investigaciones Agronómicas muestras de S. trifasciata var. "Hahnii” con síntomas foliares similares a la antracnosis causada por $C$. sansevieriae. Aparentemente, las plantas habían sido introducidas al país desde los Estados Unidos y sembradas en potes donde se presentaron los síntomas en las hojas en invernadero, lejos de la región productora de estas ornamentales en Costa Rica.

Se procesaron plantas de Sansevieria trifasciata var. "Hahnii" con lesiones foliares acuosas e irregulares tanto en el borde como en el centro de la hoja, que atravesaban ambas caras de la hoja y en algunos casos acompañados por la presencia de círculos concéntricos con coloraciones negra y naranja (Figura 1).

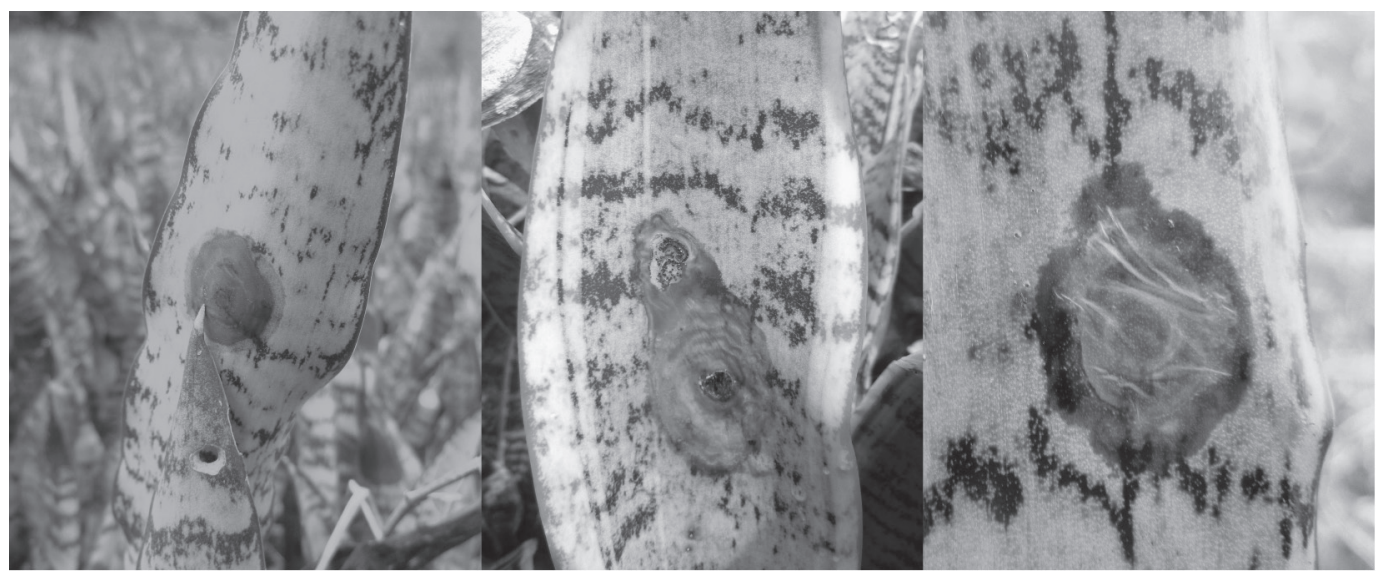

Fig. 1. Plantas de Sansevieria sp., con síntomas de antracnosis provenientes de campo.

\section{Aislamiento del patógeno}

Se tomaron segmentos de hoja (aproximadamente $0,2 \mathrm{~cm}^{2}$ ) cercanos a las lesiones, que incluían tejido sano y enfermo, se desinfectaron con hipoclorito de sodio al $1,5 \%$ por 2 min, se lavaron con agua destilada estéril y se colocaron en placas Petri con medio de cultivo papa-dextrosa-agar (PDA, Oxoid CM139) con 0,5 g. $1^{-1}$ de cloranfenicol (Sigma $($ ). Los cultivos se mantuvieron a temperatura ambiente $\left(25 \pm 2^{\circ} \mathrm{C}\right)$ y en la oscuridad. Después de 3 días, se tomó una 
sección del borde de la colonia y se transfirió a nuevas placas de Petri con el mismo medio y se colocaron bajo las mismas condiciones antes descritas.

Ante la escasa esporulación del patógeno en el medio PDA, se procedió a purificar los aislamientos por cultivo monohifal, a partir de colonias con 7 días de crecimiento. Este procedimiento se realizó en una cámara de flujo laminar y con un microscopio de luz. Se obtuvieron 5 aislamientos monohifales. La descripción de las características morfológicas de las colonias se realizó con estos aislamientos. A cada cultivo monohifal se le asignó un código de ingreso para mantener el registro de procedencia; de los mismos se conserva una muestra de micelio a $4^{\circ} \mathrm{C}$, en el Laboratorio de Biotecnología de Plantas del Centro de Investigaciones Agronómicas de la Universidad de Costa Rica.

\section{Pruebas de patogenicidad}

La capacidad de infección de los aislamientos recuperados fue evaluada mediante inoculaciones controladas con el objetivo de reproducir los síntomas de la enfermedad. Se emplearon 2 sistemas de evaluación: inoculación en hojas de plantas completas cultivadas en invernadero e inoculación en hojas separadas colocadas en cajas plásticas de $40 \mathrm{~cm}$ de largo por $28 \mathrm{~cm}$ de ancho y $15 \mathrm{~cm}$ de alto con tapa en laboratorio. El inóculo se preparó a partir de cultivos monohifales del asilamiento código Sans 3 con 15 días de edad. Se agregó $2 \mathrm{ml}$ de agua destilada estéril y se hicieron raspados con una asa micológica, a fin de obtener una suspensión del micelio del hongo.

En la inoculación bajo condiciones de invernadero se seleccionaron plantas sanas (sin lesiones o daños aparentes) y de crecimiento vigoroso. Las ornamentales se sembraron en macetas (13,5 cm de diámetro por $14 \mathrm{~cm}$ de alto) que contenían una mezcla o sustrato esterilizado en proporción 1:1 suelo-fibra de coco. La exposición a la suspensión del hongo se realizó con o sin herida en una misma hoja, con una separación aproximadamente de $4 \mathrm{~cm}$. Para provocar las heridas la hoja se pinchó 5 veces con una aguja hipodérmica estéril. En ambos casos, se depositó una gota de $20 \mu \mathrm{l}$ del inóculo que contenía las hifas del microrganismo recuperado. En 2 puntos adicionales de la hoja se realizó el mismo procedimiento con agua destilada estéril como control. Cada maceta fue regada y la planta se cubrió con una bolsa plástica transparente para mantener una alta humedad relativa (cámara húmeda).

La inoculación en hojas separadas se realizó en forma similar a la descrita por Aldaoud et ál. (2011), con ciertas modificaciones. Se tomaron hojas sanas, se desinfectaron con hipoclorito de sodio al 1,5\% por $2 \mathrm{~min}$, se lavaron con agua destilada estéril, se secaron y se colocaron sobre una rejilla metálica cubierta con papel toalla, que sirvió como base para colocar las muestras en las cajas plásticas y dejar espacio en el fondo del recipiente con el fin de aplicar una cubierta de agua para mantener la humedad relativa alta. La inoculación se realizó con y sin herida; en este último caso las hojas se pincharon 5 veces con una aguja hipodérmica estéril en 3 lugares diferentes, separados cerca de $2 \mathrm{~cm}$. En ambos casos, se depositó una gota de $20 \mu \mathrm{l}$ del inóculo descrito anteriormente. Como control se realizó el mismo procedimiento, pero se utilizó $20 \mu \mathrm{l}$ de agua destilada estéril. Luego de la inoculación, los recipientes se cerraron fuertemente con sus tapas y se mantuvieron en el laboratorio bajo luz natural por $12 \mathrm{~h}$ diarias y una temperatura de $25^{\circ} \mathrm{C}$. Las hojas se evaluaron cada 2 días durante 2 semanas hasta la aparición de síntomas.

Se evaluó la patogenicidad de los aislamientos en 7 variedades de Sansevieria trifasciata, así como en S. cylindrica, Sansevieria sp., var. Jiboia y ornamentales que se plantan en proximidad a las Sansevierias: Codiaeum variegatum (Croton), Cordelyne terminalis (Cordelyne) y Dracaena deremensis (Janet Craig), con el objetivo de evaluar el posible riesgo de que la enfermedad se propague a otros cultivos de importancia agrícola en la zona donde se siembra la lengua de suegra (Cuadro 1). 
Cuadro 1. Susceptibilidad de diferentes especies de Sansevieria y otros ornamentales de follaje a C. Sansevieriae.

\begin{tabular}{lll}
\hline Especie & Variedad & Desarrollo de síntomas \\
\hline S. trifasciata & Black gold & + \\
S. trifasciata & Coral & + \\
S. trifasciata & Hahnii & + \\
S. trifasciata & Laurentii & + \\
S. trifasciata & Zeylanica & + \\
S. trifasciata & Bantel sensation & - \\
S.. trifasciata & Sadyuri & - \\
Sansevieria sp. & jiboia & - \\
S. cylindrica & Cilindrica & - \\
Codiaeum variegatum & Excelent & - \\
Cordelyne terminalis & Auntie loupe y Florica & - \\
Dracaena deremensis & Janet Craig & - \\
\hline
\end{tabular}

+Especie susceptible, desarrollo de síntomas.

-Especie no susceptible, no presentó desarrollo síntomas.

\section{Identificación con técnicas moleculares}

Los 5 aislamientos monohifales se transfirieron a nuevas placas Petri con PDA como se describió anteriormente y se incubaron durante 15 días a $25 \pm 2^{\circ} \mathrm{C}$ y en oscuridad. Después de este período se colectó y se depositó aproximadamente $0,2 \mathrm{~g}$ de micelio en tubos de microcentrífuga de 1,5 ml. La extracción de ADN se realizó a partir de este material según el protocolo descrito por Rogers y Bendich (1988) con algunas modificaciones. La muestra se maceró en el tubo de microcentrífuga con un pistilo estéril de acero atado a un taladro de mano y se agregó $150 \mu \mathrm{l}$ de buffer de extracción (10 ml Tris- $\mathrm{HCl} 1 \mathrm{M} \mathrm{pH}$ 8,$0 ; 2,5 \mathrm{ml}$ EDTA $0,5 \mathrm{M} ; 5 \mathrm{ml} \mathrm{NaCl} 5 \mathrm{M}$ ) se continuó con la maceración y se agregó $150 \mu \mathrm{l}$ de buffer CTAB (2 g CTAB; $10 \mathrm{ml}$ Tris-HCl 1M). Se incubó a $67^{\circ} \mathrm{C}$ durante $60 \mathrm{~min}$, se dejó enfriar y se agregó $300 \mu \mathrm{l}$ de solución Fenol: Cloroformo: Alcohol Isoamílico (25:24:1), se mezcló por inversión; se centrifugó a una velocidad de $12000 \mathrm{rpm}$ durante $15 \mathrm{~min}$. La fase sobrenadante se transfirió a un tubo nuevo de microcentrifuga de 1,5 ml y se repitió el proceso con la mezcla de Fenol: Cloroformo: Alcohol Isoamílico. Posteriormente se recuperó el sobrenadante en un tubo nuevo y se agregó $20 \mu \mathrm{l}$ de Acetato de Sodio y $300 \mu \mathrm{l}$ de Isopropanol frío, se dejó precipitar el ADN toda la noche a $-20^{\circ} \mathrm{C}$. Luego se centrifugó a $13000 \mathrm{rpm}$ durante $15 \mathrm{~min}$ y se descartó el sobrenadante. Se realizaron 2 lavados con $150 \mu \mathrm{l}$ de etanol 70\% y luego se secó el ADN precipitado en una cámara de flujo laminar. Por último, el ADN se resuspendió en $50 \mu 1$ de buffer TE $(0,605$ g Trizma base $10 \mathrm{mM} ; 0,185 \mathrm{~g}$ EDTA $1 \mathrm{mM} ; 450$ $\mathrm{ml}$ de agua, $\mathrm{pH}$ ajustado a 7,4) y se almacenó a $-20^{\circ} \mathrm{C}$, para su posterior utilización. La calidad del ADN extraído se determinó por electroforesis en gel de agarosa (TopVision ${ }^{\mathrm{TM}}$, Fermentas) al $1 \%(\mathrm{p} / \mathrm{v})$.

El ADN obtenido se utilizó para amplificar mediante la técnica de reacción en cadena de la polimerasa (PCR), la región del espaciador interno transcrito, ITS ("Internal Transcribed Spacer", por sus siglas en inglés) del ADN ribosomal (ADNr), incluidas las regiones ITS1-5.8S e ITS2, con los imprimadores universales ITS5 (5' GGAAGTAAAAGTCGTAACAAGG 3') e ITS4 (5'TCCTCCGCTTATTGATATGC3') (White et ál. 1990). La mezcla de reacción de PCR tuvo un volumen final de $25 \mu \mathrm{l}$ compuesta por 11,6 $\mu \mathrm{l}$ de agua nanopura estéril, 2,5 $\mu \mathrm{l}$ de 10x DreamTaq ${ }^{\mathrm{TM}}$ Buffer; $2 \mu \mathrm{l}$ de cada iniciador $(10 \mathrm{mM}) ; 2 \mu \mathrm{l}$ de 
dNTP's (10 mM); 1,7 $\mu \mathrm{l}$ de $\mathrm{MgCl} 2(25 \mathrm{mM}) ; 1 \mu \mathrm{l}$ de BSA (20 mg. $\left.\mathrm{ml}^{-1}\right) ; 0,25 \mu \mathrm{l}$ de polimerasa (5 u. $\mu 1^{-1}$ ) DreamTaq ${ }^{\mathrm{TM}}$ (Fermentas); $2 \mu \mathrm{l}$ de ADN molde (30 ng). La amplificación se realizó en un Termociclador Applied Biosystems Veriti $^{\mathrm{TM}}$ con el siguiente programa térmico: desnaturalización inicial $94^{\circ} \mathrm{C}$ por $3 \mathrm{~min} ; 25$ ciclos bajo las siguientes condiciones $45 \mathrm{~s}$ a $94^{\circ} \mathrm{C}, 30 \mathrm{~s}$ a $61^{\circ} \mathrm{C} ; 2 \mathrm{~min}$ a $72^{\circ} \mathrm{C}$ y una extensión final durante $5 \mathrm{~min}$ a $72^{\circ} \mathrm{C}$. El producto de PCR se analizó por electroforesis en gel de agarosa (TopVision ${ }^{\mathrm{TM}}$, Fermentas) 1,6\% (p/v) con buffer $0,5 \mathrm{x}$ Tris-buffer (TBE) y $2 \mu \mathrm{l}$ de GelRed $^{\mathrm{TM}}$ (Biotium). La visualización de los fragmentos amplificados se realizó en un transiluminador (Uvisave gel documentation systems HD2 LCD ${ }^{\circ}$, UVITEC CAMBRIDGE). El fragmento amplificado se purificó con el kit QIAquick ${ }^{\circledR}$ PCR Purification Kit (QIAGEN, CA, EU), de acuerdo con las instrucciones del fabricante. Los fragmentos purificados se enviaron a secuenciar en ambas direcciones $\left(5^{\prime} \rightarrow 3^{\prime}\right.$ y $\left.3^{\prime} \rightarrow 5^{\prime}\right)$ a la compañía Macrogen, Inc., con centro de operaciones en Corea del
Sur, con los iniciadores ITS5 e ITS4. Las secuencias obtenidas para cada imprimador se analizaron con el programa BioEdit Sequence Alignment Editor version 7.0.5.3 (Hall 1999) y se obtuvo la secuencia consenso. Las secuencias obtenidas se compararon con las secuencias publicadas en la base de datos del Banco de Genes del Centro Nacional para la Información Biotecnológica en USA (National Center for Biotechnology Information NCBI), mediante la opción BLASTn search (Altschul et ál. 1997).

La información del ADN de la región ITS2 de diferentes especies de Colletotrichum, incluidas las secuencias de los aislamientos de $C$. sansevieriae obtenidos en Japón (Nakamura et ál. 2006), Australia (Aldaoud et ál. 2011) y USA (Palmateer et ál. 2012) (Cuadro 2) se obtuvieron del Banco de Genes, las mismas fueron alineadas con el programa Clustal W (Thompson et ál. 1994). El alineamiento fue corregido manualmente en el programa BioEdit. El análisis filogenético de las secuencias se hizo con el programa MEGA 5 (Molecular Evolutionary Genetics, Tamura et

Cuadro 2. Especies de Colletotrichum y número de accesión en el Banco de Genes para región ITS-2 utilizados para el análisis filogenético.

\begin{tabular}{|c|c|c|c|}
\hline Especie & Aislamiento & Origen & $\mathrm{N}^{\mathrm{o}}$. Accesión \\
\hline C. acutatum & IMI 348499 & Francia & AJ536220.1 \\
\hline C. acutatum & BBA 71427 & $\ldots$ & AJ301987.1 \\
\hline C. boninense & GK2 & Japón & AB087215.1 \\
\hline C. coccodes & MAFF 712102 & Japón & AB105970.1 \\
\hline C. dematium & MI-080025 & $\ldots$ & AB046608.1 \\
\hline C. destructivum & ATCC10921 & $\ldots$ & AF320562.1 \\
\hline C. falcatum & IMI 347765 & $\ldots$ & AJ536231.1 \\
\hline C. fragariae & IMI 345047 & $\ldots$. & AJ536223.1 \\
\hline C. gloeosporioides & BBA 71334 & $\ldots$ & AJ301974.1 \\
\hline C. lindemuthianum & MAFF 305390 & $\ldots$ & AB087222.1 \\
\hline C.musae & BBA 70365 & $\ldots$ & AJ301929.1 \\
\hline C. orbiculare & MAFF 306589 & $\ldots$. & AB042309.1 \\
\hline \multirow[t]{5}{*}{ C. sansevieriae } & Sa-1-1 & Japón & AB212990.1 \\
\hline & Sa-1-2 & Japón & AB212991.1 \\
\hline & VPRI 41498 & Australia & HQ433226.1 \\
\hline & 1016 & USA & JF911349.1 \\
\hline & 1047 & USA & JF911350.1 \\
\hline C. spinaciae & BBA 71333 & $\ldots$. & AJ301973.1 \\
\hline C. trifolii & UQ349 & $\ldots$ & AF451909.1 \\
\hline C. truncatum & 9971646 & $\ldots$ & AF451904.1 \\
\hline
\end{tabular}


ál. 2011); según el criterio de Máxima Verosimilitud (Maximum Likelihood), el modelo Kimura 2-parameter y un análisis de 5000 réplicas de Bootstrap. Se incluyó la secuencia de la región ITS2 de Magnaporthe grisea (AB031335) como grupo externo (raíz). Las secuencias de la región ITS2 utilizadas fueron las mismas que emplearon Nakamura et ál. (2006) en su análisis filogenético cuando describieron a $C$. sansevieriae como una nueva especie.

\section{RESULTADOS}

\section{Síntomas, aislamiento del patógeno y caracterización morfológica}

En las hojas infectadas se observaban lesiones redondas, acuosas y algunas alargadas, producto de la unión (coalescencia) de infecciones individuales. Daños más antiguos presentaban apariencia seca, café y con aspecto de quema.
A partir del material enfermo se obtuvo 5 aislamientos monohifales similares a Colletotrichum sansevieriae Nakamura. Las colonias en PDA se caracterizaron por una coloración crema y un micelio raso o postrado en los primeros días. A los 10 días de crecimiento, las colonias se tornan de color blanco grisáceo, parcialmente crema con hifas algodonosas aéreas. En las áreas de mayor edad (cercanas al punto de inoculación inicial) se desarrolló una coloración naranja. Al reverso, el hongo presentó un color gris-crema-rosa. En algunos casos después de 10 días se observaron estructuras de color café oscuro (Figura 2A y 2B). Observaciones al microscopio de luz revelaron que la presencia de conidios de los aislamientos cultivados en PDA fue escasa. El estudio de las estructuras del patógeno se hizo a partir de montajes de raspados de los signos presentes en las hojas inoculadas con los aislamientos puros. Los conidios fueron cilíndricos, ligeramente alargados e hialinos (Figura 2C).

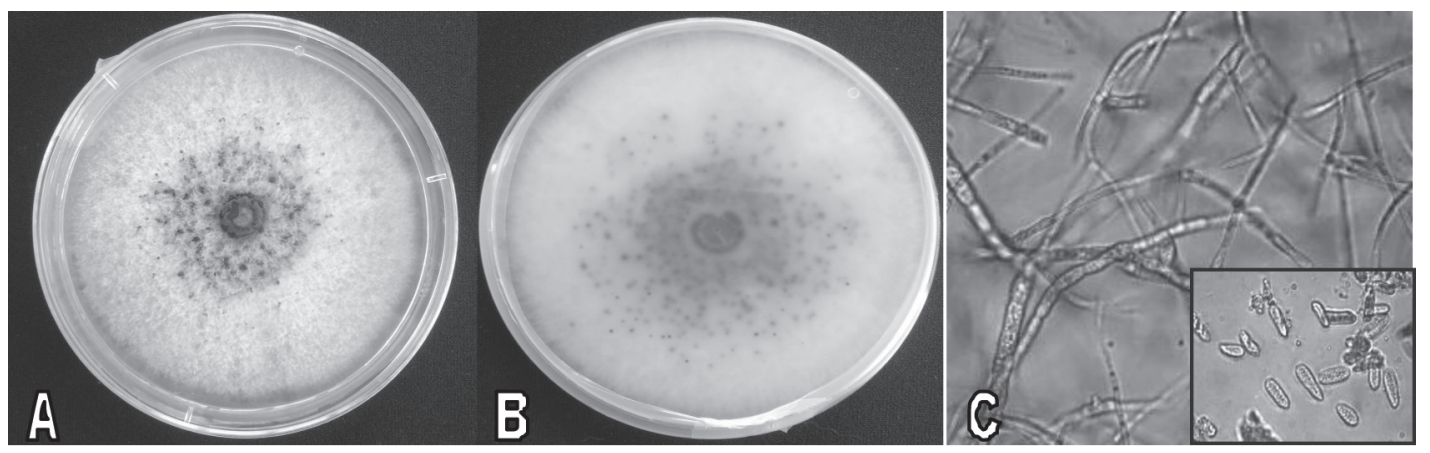

Fig. 2. Aislamiento de Colletotrichum sansevieriae obtenido a partir de hojas de S. trifasciata con 15 días de crecimiento. A) Vista frontal, B) Vista base placa, C) hifas y conidios.

\section{Patogenicidad}

En los 2 sistemas de inoculación utilizados, plantas en maceta en invernadero y hojas separadas en laboratorio, se reprodujeron los síntomas de la enfermedad. El daño ocasionado por $C$. sansevieriae se presentó únicamente cuando se hicieron heridas en la hoja con la aguja hipodérmica. La aparición de síntomas ocurrió entre 7 y 14 días después de la inoculación (DDI), aunque en algunas variedades fue más tardía. Los indicios de la infección consistieron en lesiones acuosas redondas, similares a las observadas en el material recibido inicialmente en el laboratorio para análisis (Figura 3). 


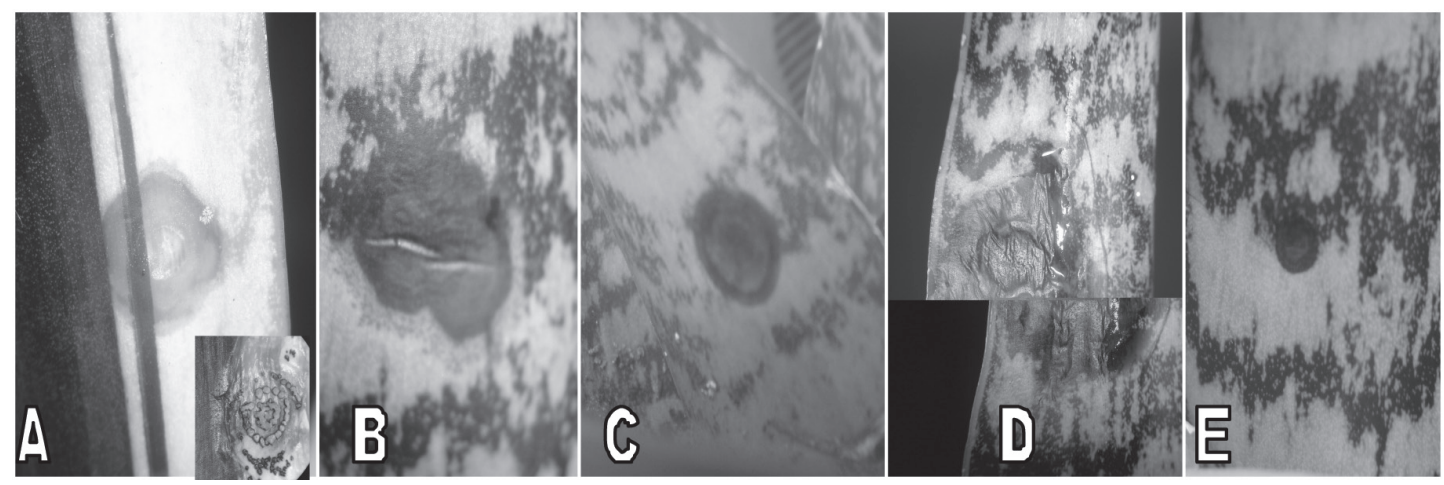

Fig. 3. Desarrollo de lesiones causadas por Colletotrichum sansevieriae en plantas inoculadas de S. trifasciata: A) Black Gold, B) Coral, C) Hahnii, D) Laurentii; E) Zeylanica.

De las 8 variedades de $S$. trifasciata evaluadas, 5 desarrollaron los síntomas de antracnosis: Black Gold, Coral, Hahnii, Laurenti y Zeylanica (Cuadro 1). El cultivar Hahnii" resultó el más susceptible. En este tipo de planta la aparición de síntomas ocurrió entre 7 y 9 DDI; mientras que en las otras como Black Gold, Coral y Zeylanica se dio después de los 14 DDI (Figura 3). Las plantas Bantel Sensation, Sadyuri y Sansevieria sp., var. Jiboia no mostraron síntomas durante todo el período de evaluación. En la especie S. cylindrica se observó un rápido proceso de cicatrización luego de la inoculación que inhibió el desarrollo de los síntomas. Tampoco se observaron pudriciones en las otras especies de ornamentales evaluadas (D. deremensis, Cordelyne terminalis y Codiaeum variegatum) que se cultivan en la misma región que $S$. trifasciata. El patógeno fue re-aislado de las hojas inoculadas. La forma y el color de la colonia fueron idénticos a la de los aislamientos obtenidos del material inicial, de manera que se cumplieron los postulados de Koch.

\section{Identificación molecular}

La amplificación mediante PCR de la región ITS del ADN ribosomal (ADNr), con los imprimadores ITS4 e ITS5 (White et ál. 1990), a partir del ADN extraído del micelio de los 5 aislamientos monohifales, produjo un solo fragmento (producto de PCR) de aproximadamente 600 pares de bases (pb).

La secuenciación directa del producto de PCR permitió obtener la lectura completa de nucleótidos de la región ITS (ITS1-5.8SITS2). Los aislamientos monohifales presentaron la misma secuencia de nucleótidos para la región ITS. En el Banco de Genes (GenBank), la secuencia se alineó con las secuencias de los aislamientos de Colletotrichum sansevieriae de Australia (voucher VPRI 41498, número de accesión HQ433226; Aldaoud et ál. 2011) y de USA (cepa 1016, número de accesión JF911349.1; Palmateer et ál. 2012) con un índice de similaridad de 99\%; y con la información del aislamiento 1047 de USA (número de accesión JF911350.1; Palmateer et ál. 2012) con un $100 \%$ de similitud. La diferencia entre la secuencia de los aislados costarricenses y los aislamientos VPRI 41498 de Australia y 1016 de USA, fue de un nucleótido en la región ITS2, una sustitución de una C por T en la posición 86 de la región ITS2 (Figura 4). La accesión 1047 de USA y los cultivos costarricenses presentan el mismo nucleótido, $\mathrm{C}$, en la posición 86. Esta misma diferencia $\mathrm{C}$ por $\mathrm{T}$, se encontró al comparar la región ITS2 de los aislados costarricenses con la información de los 2 aislamientos tipo (número de accesión AB212990 y AB212991) utilizados por Nakamura et ál. (2006) para la descripción de Colletotrichum sansevieriae como una nueva especie (Figura 4). 


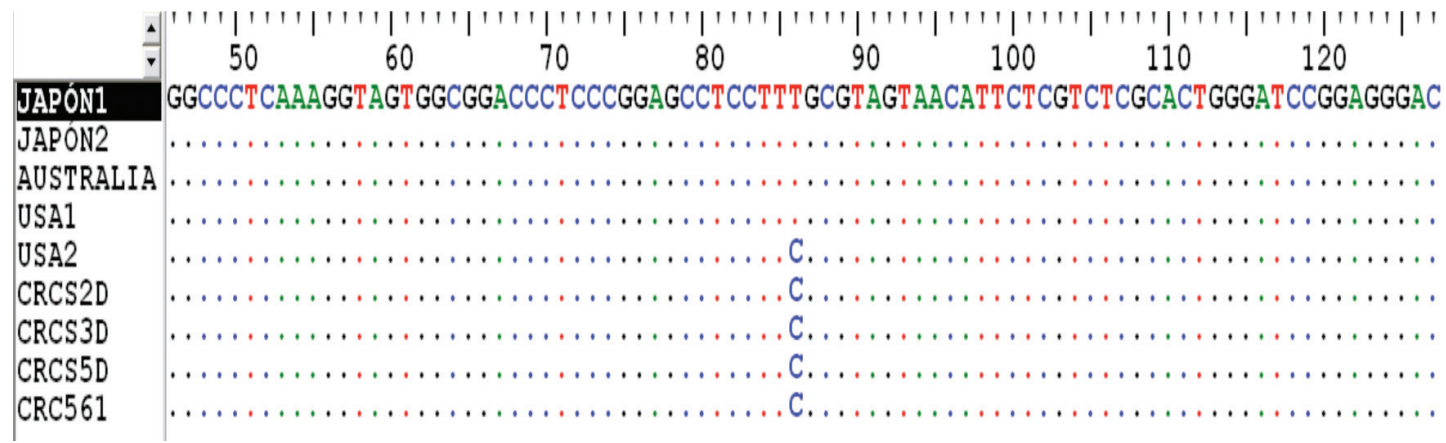

Fig. 4. Polimorfismo de nucleótido simple o SNP (T/C), observado en la región ITS-2 de aislamientos de Colletotrichum sansevieriae.

En el análisis filogenético, los cultivos costarricenses formaron un grupo único (monofilético) junto con los aislamientos de Colletotrichum sansevieriae identificados en Japón, Australia y
USA con un valor de Boostrap de 99 y separado de otras especies de Colletotrichum. Las colonias costarricenses presentaron una mayor relación con el aislamiento 1047 de USA (Figura 5).

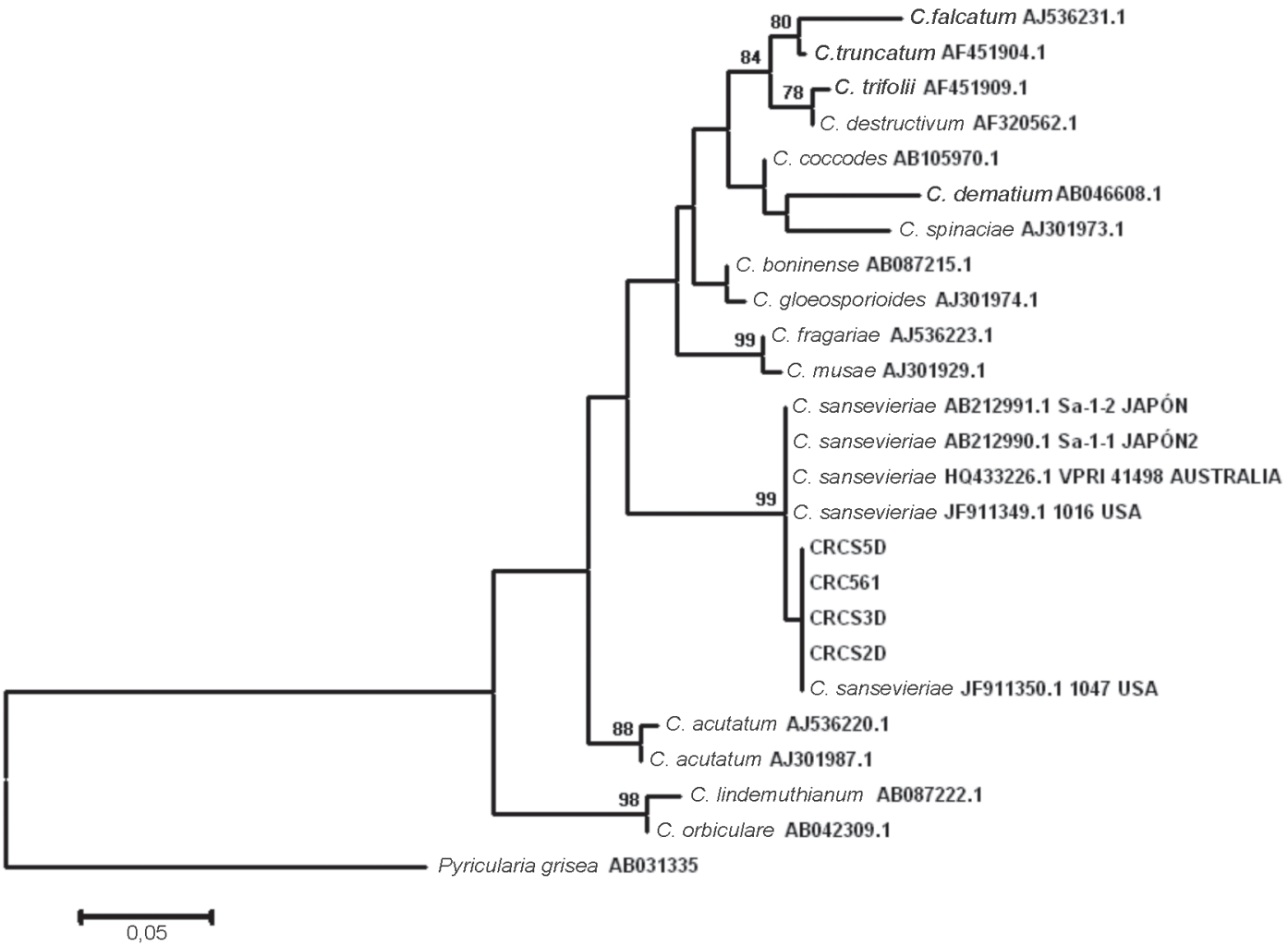

Fig. 5. Relación filogenética de especies de Colletotrichum con base en la secuencia de la región ITS-2. Árbol construido con el programa MEGA 5 software, método Máxima Verosimilitud (ML), modelo Kimura 2-parameter y 5000 réplicas de Bootstrap. Se incluyó como raíz a Magnaporthe grisea. Valores de Bootstrap se indican en los nodos. 


\section{DISCUSIÓN}

Los síntomas observados en las muestras foliares iniciales de S. trifasciata var. "Hahnii", así como en las hojas inoculadas en condiciones de invernadero y laboratorio, correspondieron a los descritos inicialmente en Japón por Nakamura et ál. (2006) para la nueva enfermedad en Sansevieria denominada "antracnosis de Sansevieria" y causada por la especie Colletotrichum sansevieriae Nakamura. Luego de esta descripción inicial, infecciones similares han sido descritos en Sansevieria, en Australia (Aldaoud et ál. 2011) y USA (Palmateer et ál. 2012).

La forma y el color de la colonia de los aislamientos obtenidos a partir del tejido foliar infectado también fueron similares a los descritos por Nakamura et ál. (2006). La producción de conidios en PDA fue escasa, a diferencia de lo informado por Nakamura et ál. (2006), esto puede estar asociado a diferencias en las condiciones de incubación de los aislamientos, temperatura y luminosidad, factores que pueden incidir en el número de esporas o conidios formados (Sangeetha y Rawal 2010, Agrios 2005). Cuando se realizaron observaciones microscópicas de preparaciones tomadas de tejido infectado, los conidios observados fueron típicos del género Colletotrichum spp., hialinos, aseptados, cilíndricos y rectos. No se determinó las dimensiones de estas estructuras.

La descripción de la enfermedad y las características morfológicas de los aislamientos (coloración de la colonia, forma y dimensión de los conidios) son útiles para un diagnóstico preliminar; pero a menudo insuficientes para la identificación del agente causal a nivel de especie. Además, la identificación de patógenos con base en características morfológicas requiere de experiencia y habilidad. Esto es particularmente relevante para algunos géneros de hongos fitopatógenos, incluido Colletotrichum, el cual puede presentar diferencias en la coloración y forma de la colonia de acuerdo con el hospedero del que se recupera, dichas variaciones hacen que se consideren especies complejas, heterogéneas y con gran variabilidad en medio de cultivo
(Sreenivasaprasad y Talhinhas 2005, Peres et ál. 2005, Hyde et ál. 2009).

Colletotrichum sansevieriae se considera un patógeno restringido a sansevierias, es decir, con un alto grado de especificidad por el hospedante, por lo que no representa riesgo para otras plantas no relacionadas. Sansevieria stuckyi y S. trifasciata son susceptibles a la enfermedad (Nakaura et ál. 2006, Aldaoud et ál. 2011, Palmateer et ál. 2012). Dentro de S. trifasciata, las variedades Red Edge, Laurentii, Hahnii y Golden Hahnii han mostrado susceptibilidad (Nakamura et ál. 2006, Aldaoud et ál. 2011). En el presente trabajo, se corroboró la susceptibilidad de las variedades Hahnii y Laurentii y se añade a la lista de cultivares susceptibles Black Gold, Coral, y Zeylanica. Un resultado destacable es que las plantas S. trifasciata: Bantel sensation, Sadyuri así como Sansevieria sp., var. Jiboia y S. cylindrica no presentaron síntomas de la enfermedad. Esto indica que dentro del género Sansevieria existe resistencia a la enfermedad. Las otras ornamentales evaluadas (D. deremensis, Cordelyne terminalis y Coidaeum variegatum) que se cultivan próximas a las Sansevieria tampoco mostraron síntomas, lo que concuerda con los resultados de Nakamura et ál. (2006).

La implementación de técnicas moleculares (análisis de ADN) para la confirmación de la identidad de los patógenos de plantas ha ganado importancia en la última década, particularmente la amplificación mediante PCR y el análisis de la secuencia de nucleótidos de la región ITS del ADN ribosomal (ITS1-5.8S-ITS2). Nakamura et ál. (2006) complementaron la descripción de Colletotrichum sansevieriae como una nueva especie y responsable de la antracnosis en Sansevieria con un análisis filogenético con base en la secuencia de la región ITS2. Aldaoud et ál. (2011), en Australia, y Palmateer (2012), en USA, obtuvieron la secuencia completa de la región ITS (ITS1-5.8S-ITS2) de aislamientos de Colletotrichum sp., obtenidos de hojas enfermas de Sansevieria. La información de la región ITS2 de los cultivos australianos fue idéntica a la de los aislamientos japoneses, mientras que para 
los aislados de USA, uno de ellos (cepa 1016) presentó una secuencia idéntica, y el otro difirió en un solo nucleótido (C por T) (Figura 5). La secuencia completa de la región ITS para los aislamientos de Australia y USA fue idéntica o varió únicamente en el nucléotido mencionado. Tanto Aldaoud et ál. (2011) como Palmateer et ál. (2012) concluyeron que Colletotrichum sansevieriae fue responsable de la sintomatología observada.

La secuencia de la región ITS de los aislamientos costarricenses y la secuencia de los aislados australianos y estadounidenses presentaron un índice de similaridad del 99 al 100\%. Cuando se comparó solo la región ITS2 de las cepas costarricenses con la de los japoneses, australianos y estadounidenses, la similitud fue de $99,8 \%$, la diferencia fue de un nucleótido en la posición 86, $\mathrm{C}$ por T. No hubo diferencia entre la secuencia de la región ITS2 de los aislamientos costarricenses y el aislamiento USA 1047 (Figura 4). Esto indica que Colletotrichum sansevieriae Nakamura fue responsable de los síntomas observados y la existencia de al menos 2 haplotipos en Colletotrichum sansevieriae Nakamura. Por otra parte, los cutivos costarricenses están más relacionados con el 1047 de USA, lo que corrobora la introducción del patógeno al país desde USA (Figura 4).

En el análisis filogenético, realizado por Nakamura et ál. (2006) los aislamientos de $C$. sansevieriae formaron un grupo único y claramente separado de otras especies comunes como C. acutatum, C. capsici, C. fragariae y C. gloeosporioides. En el presente trabajo los aislados costarricenses se agruparon con la información de las cepas japoneses, australianas y estadounidenses de $C$. sansevieriae y separados de otras especies de Colletotrichum, lo que concuerda con los resultados de Nakamura et ál. (2006) y corrobora el estatus de especie de $C$. sansevieriae como responsable de los síntomas observados.

La evidencia sintomatológica, cultural y molecular indica que las muestras foliares de Sansevieria analizadas presentaban la antracnosis de Sansevieria, causada por el hongo Colletotrichum sansevieriae Nakamura. Los postulados de Koch fueron cumplidos al re-aislar el mismo patógeno de las plantas infectadas.

Hasta donde se conoce, este es el primer informe de la enfermedad en Costa Rica. Las muestras analizadas provenían de plantas introducidas al país y que fueron erradicadas. Sin embargo, se sugiere que productores y técnicos monitoreen las plantaciones y se mantengan atentos ante la posible aparición de daños por antracnosis de la Sanseviera, la cual no sólo hace que las plantas infectadas pierdan su valor comercial, sino que su manejo y combate incrementaría los costos de producción. Además, en caso de detectarse algún nuevo caso de la enfermedad en plantaciones comerciales es necesario evitar el uso material de siembra de esos campos con el fin de contener el avance de la enfermedad por material vegetal infectado.

\section{LITERATURA CITADA}

AGRIOS G.N. 2005. Plant pathology. $5^{\text {th }}$. Ed. Elsevier Acad. Press. Burlington. Mass, EU. 251-262 p.

ALDAOUD R., DEALWIS S., SALIB S., CUNNINGTON J.H., DOUGHTY S. 2011. First record of Colletotrichum sansevieriae on Sansevieria sp., (mother-in-law's tongue) in Australia. Australasian Plant Dis. Notes 6(1):60-61.

ALTSCHUL S.F., MADDEN T.L., SCHÄFFER A.A., ZHANG J., ZHANG Z., MILLER W., LIPMAN D.J. 1997. Gapped BLAST and PSI-BLAST: a new generation of protein database search programs. Nucleic Acids Res. (25):3389-3402.

HALL T.A. 1999. BioEdit: a user-friendly biological sequence alignment editor and analysis program for Windows 95/98/NT. Nucleic Acids Symposium Series 41:95-98.

HYDE K.D., CAI L., MCKENZIE E.H.C., YANG Y.L., ZHANG J.Z., PRIHASTUTI H. 2009. Colletotrichum: a catalogue of confusion. Fungal Diversity 39:1-17.

KHALUMBA M.L., MBUGUA P.K., KUNG'U J.B. 2005. Uses and conservation of some highland species of the genus Sansevieria. African Crop Science Conference Proceedings. Vol. 7:527-532.

MINISTERIO DE AGRICULTURA Y GANADERÍA (MAG). 2007. Agencia de servicios agropecuarios La Tigra. Informe Censo de Plantas Ornamentales, Región Huetar Norte. Costa Rica (en línea). Consultado el 13 marzo 2011. Disponible en http:// www.mag.go.cr/bibliotecavirtual/a00004.pdf 
MORA F. 2008. Plan de gestión para la caracterización de la producción primaria del principal ornamental en la región Huétar Norte de Costa Rica. Tesis de maestría en Administración de Proyectos. Universidad para la Cooperación Internacional, Costa Rica. 154 p.

NAKAMURA M., OHZONO M., IWAI H., ARAI K. 2006. Anthracnose of Sansevieria trifasciata caused by Colletotrichum sansevieriae sp., nov. J. Gen Plant Pathol 72:253-256.

PALMATEER A.J., TARNOWSKI T.L.B., LÓPEZ P. 2012. First Report of Colletotrichum sansevieriae Causing Anthracnose of Sansevieria trifasciata in Florida. Plant Disease 96(2):293.

PERES N.A., TIMMER L.W., ADASKAVEG J.E., CORRELL J.C. 2005. Life styles of Colletotrichum acutatum. Plant Disease 89(8):784-796.

PROMOTORA DEL COMERCIO EXTERIOR DE COSTA RICA (PROCOMER). 2010. Estadísticas de Comercio Exterior Costa Rica, 2000. GRUPO NACIÓN. San José, Costa Rica. 240 p.

ROGERS S.O., BENDICH A.J. 1988. Extraction of DNA from plant tissues, pp. A6: 1-10. In: S.B Gelvin, R.A Schilperoort (eds.). Plant Molecular Biology Manual. Boston, MA: Kluwer Academic Publisher.

SÁNCHEZ DE LORENZO CÁCERES J.M. 2006. Las especies del género Sansevieria cultivadas en España (en línea). Consultado en 9 de marzo, 2012. Disponible en http://www.arbolesornamentales.es/ Sansevieria.htm
SANGEETHA S.G., RAWAL R.D. 2010. Temperature requirement of different isolates of Colletotrichum gloeosporioides isolated from mango. African Journal of Biotechnology 9(21):3086-3090.

SREENIVASAPRASAD S., TALHINHAS P. 2005. Genotypic and phenotypic diversity in Colletotrichum acutatum a cosmopolitan pathogen causing anthracnose on a wide range of hosts. Molecular Plant Pathology 6(4):361-378.

TAKAWIRA R., NORDAL I. 2001. The genus Sansevieria (family Dracaenaceae) in Zimbabwe. Acta Horticulturae 552:189-198.

TAMURA K., PETERSON D., PETERSON N., STECHER G., NEI M., KUMAR S. 2011. MEGA5: Molecular Evolutionary Genetics Analysis using Maximum Likelihood, Evolutionary Distance, and Maximum Parsimony Methods. Molecular Biology and Evolution 28(10):2731-2739.

THOMPSON J.D., HIGGINS D.G., GIBSON T.J. 1994. CLUSTAL W: improving the sensitivity of progressive multiple sequence alignment through sequence weighting, position-specific gap penalties and weight matrix choice. Nucleic Acids Res 22:4673-4680.

WHITE T.J., BRUNS T., LEE S., TAYLOR J. 1990. Amplification and direct sequencing of fungal ribosomal RNA genes for phylogenetics, pp. 315322. In: M. A. Innis, D.H. Gelfand, J.J. Sninsky and T.J. White (eds.). PCR protocols: a guide to methods and applications. Academic Press, San Diego, EU. 